\title{
THE ADOLESCENCE: SCHOLASTIC SUCCESS AND FAILURE
}

Gabriela Negoiță (Păcurariu)

West University of Timișoara, Faculty of Sociology and Psychology

(C) 2016 Gabriela Negoiță (Păcurariu)

This is an open access article distributed under the Creative Commons Attribution-NonCommercial-NoDerivs license (http://creativecommons.org/licenses/by-nc-nd/3.0/)

DOI: $10.1515 /$ eras-2016-0004

\begin{abstract}
The research described herein has taken into consideration the manner in which high school pupils conceive the scholastic success or the scholastic failure, in times of adolescence, taking acount of this moment of life. At the same time, this research intents to highlight the degree of motivation the pupils posess, taking into consideration the school requirements, as well as the role of the teacher-pupil relation in this context. The subjects of the sample have been selected from amongst XI ${ }^{\text {th }}$ grade pupils of Colegiul Național Bănățean (high school - Ed.) in Timișoara. The tool that has been employed for data collection has been adapted to the pupils' level of cognitive and emotional development, considering their age particularities.
\end{abstract}

Keywords: adolescence, scholastic success, scholastic failure, motivation, teacher-pupil relation

\section{Introduction}

The adolescence is the period of human development which follows the stage of childhood and preceeds the stage of young adult. It is also known as the period of the mature scholar. Generally, this period defines the age intervals of $14 / 15$ and $18 / 19$ years old, depending on each person's particularities. Crossing this moment reflects reaching maturity, physical, psychical and social development. The adolescence - a stage that is specific to the second decade of a person's life span - is characterised by reaching maturity and obtaining integration into the adult society which implies social, political, family and professional requirements, etc.

Jean Piaget believes that adolescence refers to the interval between 15 and 18 years old. Other researchers divide the periods from 11 to 20 years old in four stages: preadolescence, early adolescence, middle adolescence and late adolescence. On the other hand, Ursula Șchiopu and Emil Verza propose other stages of adolescence: preadolescence, actual adolescence (16-18 to 20 years old) and extended adolescence which refers to youth implicated in work or study programms $(18 / 20-25$ years old $)$.

This age is sub-divided as follows:

- Stage of puberty $(10-14 / 15$ years old $)$ dominated by an intense growth;

- Stage of adolescence (14/15 - 18/20 years old) dominated by the adaptation to the adult status and by the process of independece gain and significant intellectualization of the behavior;

- Stage of extended adolescence (18/20 - 24/25 years old) dominated by the primary psychological integration into the requirements of a profession, into the condition of independece and marital status (Șchiopu, U., Verza, E., 1997).

According to Ursula Șchiopu and Emil Verza (1997), the adolescent runs through 
certain stages:

- Preadolescence - this is a stage of stabilization in terms of biological maturity. It is in this moment that the individualization is outlined and deepened. It is a stage of intense psychical development that is full of internal conflicts. The pupil still shows a certain restlessness and a certain impulsivity, some extravagances, moments of anxiety, moments of difficulty, concentration, fatigue to effort. Personal opinions are starting to be argumented and are often validated by generation ("times have changed", "when we were young"). The desire of personal affirmation is dominating, and this desire determins the pupil to focus his interests on activities which he believes are defining for his person;

- Actual adolescence or the great adolescence - characterised by intense intellectualization. During this stage, the adolescent seeks for personal means of being and appearing in front of others. He accepts multiple responsabilities. From forms of impulsive evaluation, the adolescent passes to forms of evaluation where he could express his originality;

- Extended adolescence - refers to pupils who have already been integrated into forms of work and also students. In one way or another, independence is gained or about to be gained at this age. The personal style and the behavior that defines personality are developed. The sentimental side of life is intense but relatively unstable. Marital engagements are also specific to this stage of adolescence (the pupil is now capable of forming a family). At this moment, intimacy does not only refer to sexuality but also to friendship and bonds.

Scholastic success / failure can be defined as "the degree of adequacy between the level of psycho - physical development of the pupil and the objective requirements at which he is subjected during the learning process". The notions of success - failure, achievement downfall in an activity are qualitative notions which refer to the degree of accomplishment through an activity - of certain interests, personal objectives but also to the fulfillment of certain external, normative requirements. The grades, the status of "good" or "bad" pupil, failure or success in exams are aspects which directly influence the pupil's position inside his family and his group of friends, the family's reputation, the social perception of that family, the quality of family education.

The school itself is evaluated by the social community depending on the grades that are obtained by its pupils. In this context, scholastic success has become some sort of quality standard for all the elements that are involved in this process (pupils, teachers, parents, schools, social community) while scholastic failure or downfall determines the depreciation of the pupil, of the school and of the family. On most occasions, it becomes synonym with life failure, since the downfall is no longer a pedagogical problem but a social one (Sălăvăstru, 2004).

Quite often, scholastic failure has been defined by referring to what its opposite, the scholastic success represents. In between the scholastic success and the scholastic failure, there is a dynamic, dialectic and complex relation. As success cannot be complete and continuous, it cannot be indefeasible and global. The phrase "scholastic failure" is alternatively employed with the phrase of "scholastic downfall", the two being considered up to a certain point as synonyms. The term"scholastic failure" has a smaller emotional meaning and a less negative psychological impact, thus offering a more optimistic perspective on recovery possibilities (Sălăvăstru, 2004).

The notions of "scholastic success" and "scholastic failure" are not timeless. They are 
imposed by social history. The scholastic success implies: "obtaining superior efficiency in the instructive - educational activity, in terms of requirements, programms and teaching outcomes", while failure refers to : "lack of progress in learning or non-fulfillment of mandatory requirements in the instructive - educational process, as an effect of a discrepancy between requirements, possibilities and results (Popescu, 1991 apud Sălăvăstru, 2004).

Success / failure has a generally individual, subjective nature and depends on the relation between performances and objectives, while achievement / downfall, in terms of external regulations and standards that are implemented through scholastic mechanisms has a higher degree of objectivity.

Failure can be:

- Generalised - (difficulties in adapting to the school life as a whole) and limited (difficulties in some / one discipline);

- Cognitive - (non-fulfillment of scholastic objectives - condition, repeat) and non cognitive (maladjustment to scholastic requirements);

- Episodical (short) or long-lasting.

According to Sălăvăstru (2004), the stages of failure are:

- The preceding stage- the occurrence of the first problems in the accomplishment of school tasks and in psychological terms, the pupil's discontent concerning school, his lack of interest and desire to further learn;

- The stage of actual declension - characterised by the accumulation of large knowledge gaps and the abhorrence to learning, teachers and scholastic authority, various forms of denying school activities ;

- The stage of formal downfall - indicated by repeat or dropout.

The causes of scholastic failure are of triple nature:

Family causes:

- dysfunctional families;

- lack of conditions that are necessary for life (food, clothes, footwear, housing);

- lack of learning conditions;

- undue requirements from parents who demand unfeasible results to their children;

- lack of control over scholastic and extrascholastic activities from parents;

- authoritative behavior of parents who apply restrictions and undue sanctions to children;

- lack of connection between some parents and school, teachers, class master.

Physio - psycho-sociological causes:

- physiological disorders such as sensorial disorders (aural, visual), certain heart, biliary, digestive, endocrine diseases (illnesses), etc;

- psychical behaviour disorders of a neurotic, mental, affective or character related nature;

- psycho-social disorders consisting in possible conflicts with ethical and social standards, following disorders of social and interpersonal relations inside the social group of the pupil. 


\section{Pedagogical causes:}

- inappropriate quality of school organization;

- inappropriate training of teachers;

- inappropriate educational content as compared to the contemporary requirements;

- inappropriate technical-material and didactic base;

- lack of cooperation between teachers which can lead to pupils and students being overloaded;

- inappropriate scholastic and professional orientation;

- subjective evaluation which wrongs and unmotivates pupils;

- passive and inappropriate didactic methodology for an active and heuristic participation of pupils to the instructive - educational process;

- insufficient contribution of media and other educational factors in sustaining the role of school.

Strategies and conditions that are favorable to the prevention and elimination of scholastic failure are established depending on the causes of scholastic downfall (family, psycho-socio-physiological and pedagogical).

Self-efficacy is defined as"the trust of a person in her own capacity of mobilization of cognitive and motivational resources required to successfully fulfill certain tasks" (Bandura, 1986, 1993 apud Gherasim and Butnaru, 2013).

According to Bandura, there is a series of factors which can influence the perception of pupils on their own competences. First, previous performances: previous achievements and downfalls can represent landmarks for evaluating possible tasks. Second, the pupil evaluates his own competence by comparing it with other people's competences in solutioning the same task. The third factor has to do with the adolescent's certitude that he is capable of accomplishing a certain task (Gherasim and Butnaru, 2013).

Motivation describes what determins, makes and helps people finish various tasks (Pintrich 2003 apud Gherasim and Butnaru, 2013).

Representing a source of the activity, motivation is considered to be the engine of personality. The motivation of learning is subordinated to the general meaning of the concept of motivation and it refers to all the factors which mobilize the pupil for an activity mean to lead to the assimilation of knowledge. Motivation energizes and facilitates the learning process through the enhancement of effort and the pupil's focus by creating a state of preparation for the learning activity. (Sălăvăstru, 2004, p.69-70).

For all the levels of education, the pupils' motivation represents one of the most important defining factors of scholastic success (Griffiths, Sharkey and Furlong, 2009 apud Gherasim and Butnaru, 2013).

Scholastic motivation represents the force which conducts, energizes and regulates pupils' behavior in school (Sălăvăstru, 2004). When asked what determines them to learn, pupils can offer very varied answers: they learn in order to work in a certain domain at a later time, in order to succeed in life, in order to obtain good grades, out of ambition to outstrip the others, in order to be praised by parents and teachers, etc.

The most important forms of motivation that are opposed one to another when it comes to learning, are:

- Intrinsic motivation originates in the activity itself and is attained through fulfilling that activity. This type of motivation determines the individual to participate at an 
activity for the pleasure and satisfaction it triggers, without the constraint of external factors. The basic form of this type of motivation is epistemic curiosity which reflects the need to know, to widen the level of knowledge. A learning activity that is intrinsically motivated is supported by the internal need, by the passion for a certain domain and it implies a relatively low effort. It involves feelings of satisfaction, content, accomplishment, leading to long lasting assimilation.

- Extrinsic motivation originates outside the individual. The engagement in an activity is conceived as a means of accomplishing the purpose and not as a purpose itself. In this situation, learning is carried out following a request and an external conditioning, without an interior pleasure, without offering direct satisfactions and with an increased individual effort. This type of motivation is accompanied by negative (fear of failure, fear towards punishment) or positive but little employed emotional elements (expectation of praise, of a good grade, of material reward).

In the educational practice, it has been observed that learning is motivated both intrinsically and extrinsically (Sălăvăstru, 2014, pp. 84-85)

\section{Concerns / research / theoretical models}

Psychological research concerning this period is focused on two opposite positions: the adolescence as a period of development marked by disorders and as a normal period of development.

Older research papers which support the first position assign to this period the normality of crisys and conflicts with the world of adults (Hyatt-Williams 1975; Mussen, 1970). Representatives of the psychoanalytic theory such as Sigmund and Anna Freud, Ernst Kretschmer (Branwhite, 2001) have claimed that the adolescence in itself posesses a pathologic, distructive character, which can predispose to the emphasis of neurotic, psychotic symptoms or schizoid characteristics. While the upholders of the idea of adolescence as normal period of development have accepted the anthropological paradigm according to which the adolescence is a period during which significant changes take place and a series of problems may occur, they have admitted that there is not necessarily a relation of cause between the two (Coleman, 1989 apud Gherasim and Butnaru, 2013). According to Steinberg (2008), major changes in this period have been grouped as it follows: physiological, cognitive and social.

The impact of various factors such as support, autonomy, structure of the environment or the quality of interpersonal relations on social, cognitive or scholastic development of pupils and adolescents has increased in the last years. (Brown, Jones, LaRusso and Aber, 2010). Numerous researches have shown that the social support which is perceived during adolescence is positively associated with the social, emotional and behavioral development of pupils (DeRosier, Kupersmidt and Patterson, 1994). The results of the researches have shown that adolescents who perceive their parents, their colleagues and/or their teachers as being supportive obtain much better school results as compared to those who do not perceive these sources as being supportive. Eccles (2004 apud Gherasim and Butnaru, 2013) shows that perceived support can indirectly influence the school results, through motivational and affective mechanisms

In the reformulated model of the lack of hope, the authors suggest that the lack of support from behalf of parents and teachers (who have unrealistic expectations, examination oriented curriculum, authoritarian classroom climate) can facilitate the development of the lack of hope expectancy, which at its turn, can determin the decrease of scholastic performances (Au, 1995; Ames and Archer, 1988 apud Gherasim and Butnaru, 2013). The 
supportive behaviour of teachers is important for pupils' scholastic results since teachers can directly conduct the learning activities through the various strategies that can be employed, they can stimulate the motivation for learning and they can influence the pupils' behaviour through rules that are issued for classroom activities (Vermunt, 1999).

In a study carried out by Gherasim, Butnaru, Boza et al (2011 apud Gherasim and Butnaru, 2013) where the global support from teachers has been measured according to dimensions such as supportive attitude, learning tasks orientation and relation equity, positive effects on scholastic performances in mathematics from VIII ${ }^{\text {th }}$ grade pupils have been noticed. Other positive results but in exact sciences (mathematics, physics, chemistry and biology) having teacher support as a background have been observed at pupils from the VIII ${ }^{\text {th }}$ grade, after measurements on dimensions such as supportive attitude and equity. The results have again been presented by.

The support from colleagues which has been perceived as cohesion and cooperation inside the classroom group, has contributed to the explanation of scholastic performance of adolescents (Gherasim, Butnaru and Iacob, 2011b; Gherasim, Butnaru et al, 2012).

Researches carried out in the field of self-efficacy by Bandura et al (2001) have indicated that, the more the pupils perceive themselves as having a higher level of selfefficacy, the more they will persevere in obtaining good scholastic results. At the same time, they will have a lower risk of school dropout (Quiroga, Janosz, Bisset and Morin, 2013 apud Gherasim and Butnaru, 2013). Strong positive correlations have been obtained between selfefficacy, long term motivation and expectancies concerning the future results of adolescents having various ages. (Bandura, Kerpelman and Mosher, Schunk apud Gherasim and Butnaru, 2013). Some studies have indicated significant and positive correlations between perceived self-efficacy and obtained scholastic performances. Longitudinal studies have identified the fact that self-efficacy is a good predictor of grades obtained during the years of secondary and high school (Gherasim and Butnaru, 2013).

In school, better results are obtained in classes where teachers express confidence and openness towards pupils, stimulating them intellectually through interesting learning tasks. The expression of a kind and supportive attitude from behalf of the teacher, the demonstration of care for the scholastic progress of pupils, the correctness and the impartiality in the evaluation process are essential components of a teacher that are meant to stimulate selftrust and implication in learning and increasing school performance for pupils (Midgley et al, 1989 apud Gherasim and Butnaru, 2013).

The teacher - pupil relations have been characterized by attributes such as: closeness, conflict, dependence (Pianta, 1999), fondness, trust, involvement, expectancies (Murray, 2009), obedience, encouragement and respect. Studies have shown that the perception of positive relations with teachers facilitates academic motivation, the social responsibility acting as a protective factor in the situation of exposure (Wentzel, 1998, Wentzel and Battle, 2001 apud Gherasim and Butnaru, 2013). Relations that are based on care, fondness, respect, have a positive influence on aspirations, the concept itself, learning strategies and academic results of adolescents. The sensibility of teachers regarding pupils' problems can influence school attendance itself through messages concerning pupils' potential of success or failure, messages that are communicated by teachers.

The correctness, the self-efficacy regarding learning and discipline, offering help, support, the feedback received after solving learning tasks, the valorization of answers and ideas of pupils facilitate the engagement in the activity of learning and the school results (Ahmed and Colab, 2010, Dotterer and Lowe, 2011 apud Gherasim and Butnaru, 2013).

There have been various theoretical approaches that have been used over the years, in order to explain the relation between scholastic motivation and performance. 
Such approaches are (Gherasim and Butnaru, 2013, p.73):

- The attribution theory

- The expectancy - value theory ;

- The goal orientation theory ;

- The theory of self - efficacy .

\section{The methodology of research}

By following the general objective of this research: "the determination of the perception that pupils from the XI ${ }^{\text {th }}$ grade of C.N Bănățean have towards the educational success and the awareness of its importance in their subsequent social integration" it has been established that the sociological investigation through a questionnaire applied to pupils is for the moment, the most adequate method of data collection in order to confirm or deny the hypothesis that scholastic performance is directly proportional to the pupils' motivation of learning.

In order to quantify scholastic performance, we have only taken into consideration the annual averages of pupils, as it came out of the school situation at the end of year 2013-2014. Pupils were also asked to write their average on the previous school year at the end of the questionnaire. The questionnaire was anonymous.

\section{Dimensions of the questionnaire:}

- Motivation (intrinsic / extrinsic)

- Integration in the school / institutional environment

- The teacher - pupil / pupil - teacher / pupil - pupil relation

- Scholastic performance

By establishing the following specific objectives, we have conceived certain outlines of the research theme, according to the aforementioned dimensions, as follows:

- Q1. Identifying pupils' perception towards the instructive - educational process in their school;

- Q2. Highlighting problems, malfunctions which mark the relation pupil - teacher and pupil;

- O3. Determining the degree of motivation of pupils for subjects from the school curriculum;

- O4. Quantifying the level up to which the pupils are integrated into the educational institution they are part of.

\section{Research hypotheses:}

- H1. Scholastic performance is directly proportional to the pupils' motivation of learning;

- H2. The better the pupils get integrated into the school where they are learning, the higher their motivation of learning;

- H3. The dialogue teacher - pupil / pupil - teacher is a determinant factor for the achievement of scholastic success by pupils. 


\section{Sample}

For this research, the sample has consisted of 86 pupils from the $\mathrm{XI}^{\text {th }}$ grade, out of which $29.1 \%$ were boys and $70.1 \%$ were girls. The pupils were selected from C.N Bănățean in Timișoara.

In order to analyse the pupils from the sample, we have employed the sociological investigation as a method, while the instrument used in this research was that of the selfassessment questionnaire. When elaborating the questionnaire, age particularities of respondents were taken into consideration (cognitive and emotional development). Questions were phrased so that the choice of the answers could be as simple as possible, but at the same time, so that established objectives and hypotheses could be achieved and the required time for questionnaire completion could be as short as possible.

\section{Results}

Following the data collection on field, we have designed a database comprising all the variables form the questionnaire, in SPSS 20. In order to be able to verify the confirmation or the denial of the hypotheses, as well as to achieve the objectives from which we have started this request, we have applied techniques of descriptive statistics, thus calculating the percentage distribution for the variables we have used in the research.

Results for the items with choice answer:

To test hypothesis 1, we have applied the Pearson $r$ correlation coefficient, obtaining the following results (Table 1):

\begin{tabular}{|c|c|c|}
\hline Correlation & & Motivation \\
\hline Performance & Pearson Coefficient & $.430^{* \pi}$ \\
\hline & Signification & .000 \\
\hline
\end{tabular}

Where $\mathrm{r}(84)=.44, \mathrm{p}<0.01$, so results are statistically significant, supporting the hypothesis according to which scholastic performance is directly proportional to pupils' motivation of learning. In other words, people who obtain high scores for the scholastic performance dimension, also obtain high scores for motivation.

Performance determines the level of motivation, the willingness to get involved, but at the same time, motivation can be strengthened by previous successes.

To test hypothesis 2, we have applied the Pearson $r$ correlation coefficient, obtaining the following results (Table 2): 


\begin{tabular}{lcc}
\hline Correlation & & $\begin{array}{c}\text { Integration into the } \\
\text { school environment }\end{array}$ \\
\hline Performance & Pearson Coefficient & $.245^{*}$ \\
& Signification & .011 \\
\hline
\end{tabular}

*. Correlationissignificant at the 0.05 level (1-tailed)

Table 2 - Indices of correlation of associating performance with integration into the school environment

The results support the hypothesis according to which a successful integration into the school environment determines the growth of motivation for learning $(r(84)=.245, p<0.05)$ Thus, when one of the variables grows, the other one grows too.

After applying the techniques of descriptive statistics for the variable called motivation, it came out that $76.7 \%$ of pupils are motivated to learn, while $23.3 \%$ of them are not.

For the variable ,intensity of motivation towards school activities”, results are shown in the following chart:

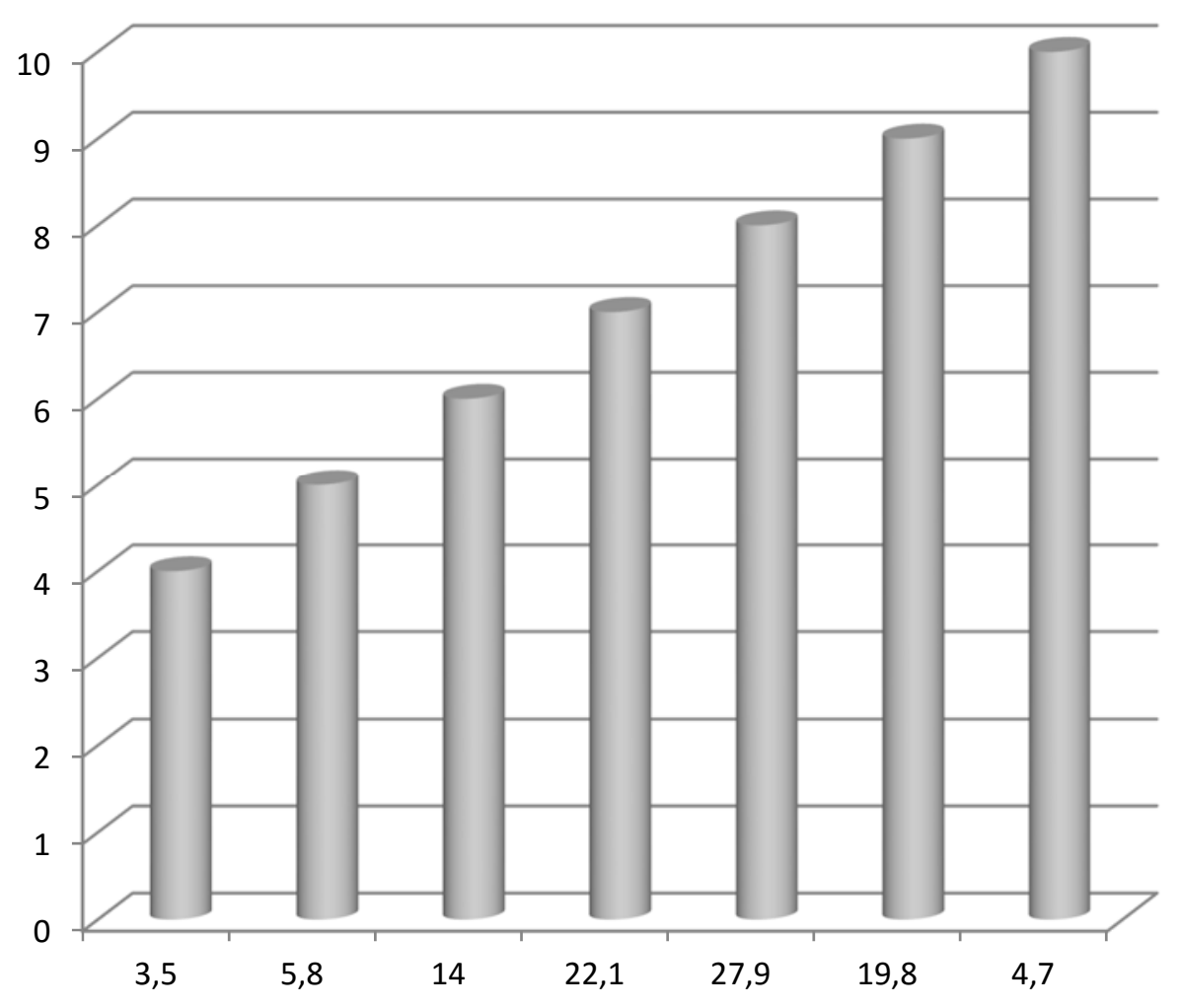

Percentage indices regarding the intensity of motivation for school activities on a scale from 1 to 10

For the variable sources of motivation, answers show the fact that $32.6 \%$ of the respondents are learning with pleasure (an intrinsic motivation), 30.2\% of them learn because they have to, because it is necessary; the need of having good grades, reflected in $30.2 \%$ of the answers while the motivation determined by family expectancies was shown in $12.8 \%$. We have identified sources of the lack of motivation, as follows: $12.8 \%$ of cases consider that 
grades are not deserved, thus the lack of involvement from pupils in the learning activity, $33.7 \%$ of pupils claim that they are not interested in school activities while $14 \%$ of answers reflect an indifference of teachers towards the pupils' needs.

For the variables „success” and „professional integration”, we have elaborated the frequency distribution, where it came out that $79.1 \%$ of the respondents see success as being important and ensuring professional integration. 95.3\% of pupils have claimed that the high school in which they learn is a success determining environment, an aspect that can be observed in results of the percentage frequencies for the variables „high school” and „success of pupils". For $36 \%$ of the respondents, school is an occasion of meeting friends, while $17.4 \%$ of them consider school as an opportunity to have fun.

For the $3^{\text {rd }}$ hypothesis which is intended to demonstrate the role of the teacher - pupil and pupil - teacher communication as being a determinant factor of scholastic success, we have applied the techniques of descriptive statistics and calculated the percentage frequency for the role of the teacher according to each pupil, as follows:

- The teacher's role is that of helping me: $70.9 \%$ have responded with yes and $29.1 \%$ have responded with no

- The teacher's role is that of understanding me: $24.4 \%$ have responded with yes and $75.6 \%$ have responded with no;

- The teacher does not understand me: $11.6 \%$ agreed with this statement, and $88.4 \%$ were not;

- The teacher has a hostile attitude: $7 \%$ answered with affirmative and $93 \%$ responded with negative.

These data demonstrate the importance of the communication between teacher and pupil, as well as the fact that a wider openness from behalf of the teacher can contribute to the growth of interest towards school and implicitly to performance growth and intrinsic motivation growth. Thus, hypothesis 3 is confirmed. The traditional style of teaching on a smaller scale is a need that has been manifested by pupils. According to them, teaching requires more model and example illustration techniques.

\section{Free answers}

For the following questions, respondents have offered few answers for the other option, thus we preferred to enumerate each and mention the occasions when same answers were given.

„Which are your sources of motivation when it comes to school activities?”: my future depends on study, I believe that intense study leads to professional success; finding a job; I want the independence that knowledge can offer to me.

„I am not motivated to learn because”: at some subjects, teachers give grades that are not deserved; at others, their manner of teaching is very vague; fatigue ( 2 answers); I am not interested in some subjects; I cannot concentrate for a long period of time; I mostly dislike what we are learning at school, there is a high amount of theory and ART is missing!!!; some classes do not match with what I intend to do further.

„How do you excuse your absences when you do not come to school?" : the teacher's way of teaching is not clear and coherent; I lose the tram; I don't wake up; Illness (14 answers); fatigue (6 answers); sports causes ( 2 answers).

Judging by the free answers given by pupils, a few very clear directions are outlined, as far as expectations, discontents or pupils' proposals concerning the way classes are held 
and the relation teacher - pupil are concerned.

When being asked „What do you think that might increase school attendance?” most pupils refer to:

- the need to modify the teaching style of some teachers (diversified methods, interactive, more interesting methods, less dictation, more practice, more explanations);

- the necessity of behavioural change from behalf of teachers (less bored teachers who are more motivated in their activity, more sociable, encouraging, sympathetic, more opened with pupils, less demanding);

- the reduction of the number of classes, a shorter program since pupils are feeling tired; (a frequent claim)

- more attractive subjects that could please all pupils; there are too many unnecessary subjects;

- a more severe regulation regarding absences / fining pupils who have a large number of absences.

When asked about what they dislike during classes, pupils have preponderantly given answers referring to:

- the disapproval of classes during which they are supposed to write much, based on dictation (approximately 20 respondents have mentioned this aspect), sometimes without any explanations, without the active involvement of pupils; on other occasions, pupils receive explanations at a fast pace, they are not requested a feedback and they have to memorize information;

- the disapproval, on equal terms, of classes where they are frequently examined with a high level of exigency and improper evaluation (they do not receive grades according to their actual knowledge);

- learning useless things;

- cases when pupils are inculcated fear by teachers (they scream, they lack patience, they are stressful and too exigent).

When asked about what pleases them the most during classes, pupils have given answers out of which we can extract the following conclusions:

- they are feeling well during classes where they can interact, participate to debates, work in team, elaborate projects, give examples from everyday life, say jokes;

- the teacher creates a peaceful, pleasant climate, he is close to them, he treats all pupils equally, he gives them the opportunity to capitalize their knowledge, he encourages them to ask questions without any fear, he is involved, he brings into discussion other interesting aspects (we learn how to carry it off well). 
Answers to the question „In your opinion, what could help you obtain better grades?" Have been diverse:

- giving up performance sport;

- changing teacher's attitude and manner of teaching;

- studying only subjects that are specific to the class profile;

- team work, projects;

- more time;

- if I would learn / strive more (32 answers).

At the same moment of the research, two suggestions concerning the teaching and evaluation processes have been made:

- the school year should be divided into teaching periods and evaluation periods;

- a different application of the teaching - examining system, the division in two periods.

\section{Conclusions}

According to results obtained in this research, we can extract the following conclusions:

- People with high performances show a stronger motivation.

- The integration into the school environment contributes to the growth of motivation.

- The dialogue between teacher - pupil, pupil - teacher represents an important factor for pupils' success; Pupils consider that teachers help them through the information they convey, but they do not understand them.

- The correlation of school subjects with a proper scholastic and professional orientation are aspects that could contribute to the growth of motivation and the attainment of better results.

- The independence given by new knowledge and the possibility of a good future job are sources of motivation that have been identified on the studied group.

\section{References}

Bandura, A., Barbaranelli, C., Caprara, G.V. \& Pastorelli, C. (2001), Selfefficacy beliefs as shapers of children's aspirations and career trajectories, Child Development, 72, 187-206.

Branwhite, T. (2001), Helping Adolescents in Schools, Westport: Praegers Publisher.

Brown, J. L., Jones, S. M., LaRusso, M. D. \& Aber, J. L. (2010), Improving Classroom Quality: Teacher Influences and Experimental Impacts of the 4RsProgram, Journal of Educational Psychology, 102(1), 153-167.

Gherasim, L.R., Butnaru, S. (2013). Performanța școlară - Determinanți individuali şi contextuali în adolescență, Iași: Editura Polirom.

DeRosier, M., Kupersmidt, J.B. \& Patterson, C.J. (1994), Children's academic and behavioral adjustment as a function of the cronicity and proximity of peer rejection, Child Development, 65, (6), 1799-1813.

Gherasim, L.R., Butnaru, S., \& Iacob, L.M. (2011b), The Motivation, Learning enviroment and School Achievement, The International Journal of learning, 17(12), 353-363.

Gherasim, L.R., Măirean, C. \& Butnaru, S. (2012), Prediction of School Performance: The Role of Motivational Orientation and Classroom Environment, Procedia Social and Behavioral Science, 46, 3921-3935. 
Hyat-Wiliams, A. (1975), Problems of homosexuality, British Medical Journal, 3, 426-428.

Murray, C. (2009), Parent and teacher Relationships as predictors of School Engagement and Functioning among Low-Income Urban Youth, Journal of Early Adolscence, 29(3), 376-404.

Mussen, P. H., Conger, J. J. \& Kagan, J. (1970) Reading in Child Development and Personality, Londra: Harper\& Row.

Pianta, R.C. (1999), Enchancing relationships between children's and teachers, Washington, DC. American Psychological Association.

Sălăvăstru, D. (2004) Psihologia educației. Iași: Editura Polirom.

Şchiopu, U., Verza, E. (1997). Psihologia vârstelor - ciclurile vieții, București: Editura didactică şi pedagogică. Steinberg, L. (2008), Adolescence, ed. a VIIIa, New York: McGraw-Hill.

Vermunt, J.D. \& Verloop, N. (1999), Congruence and friction between learning and teaching, Learning and Instruction, 9, 257-280. 